\title{
Pengaruh Kualitas Produk, Price fairness, Citra Merek dan Kepercayaan Merek Terhadap Kepuasan Pelanggan Handphone Merek Samsung di Banjarmasin
}

\author{
Abul Hasan Asy'ari', \\ Email : abulhasan.asyari96@gmail.com \\ Anthonius Junianto Karsudjono ${ }^{2}$ \\ Email: tonimbbm@yahoo.com
}

\begin{abstract}
:
This study aims to determine the effect of Product Quality, Price Fairness, Brand Image, and Brand Trust variables on Customer Satisfaction of Samsung brand mobile phones. This research is a correlational study with the population is all people who own and use Samsung mobile phones that meet the requirements for respondents. The sample in this study was 125 respondents. The results showed that (1). Simultaneously the Product Quality, Price Fairness, Brand Image and Brand Trust variables significantly influence Customer Satisfaction (2). Partially, Product Quality and Price Fairness variables have no significant effect on Customer Satisfaction. Whereas the Brand Image variable, Brand Trust has a significant effect on Customer Satisfaction.
\end{abstract}

Keywords: Kualitas Produk, Price fairness, Citra Merek, Kepercayaan Merek dan Kepuasan Pelanggan. 


\section{PENDAHULUAN}

Perkembangan teknologi informasi berkembang sangat pesat semenjak ditemukannya telepon genggam atau ponsel, hal ini terjadi ponsel memiliki sifat yang fleksibel sehingga dapat dibawa kemana-mana. Dengan sifatnya yang mobile tersebut membuat pengguna ponsel semakin hari semakin meningkat. Hal ini tidak terlepas dari kebutuhan masyarakat terhadap ponsel sangat tinggi yang digunakan sebagai alat komunikasi dan menunjang segala aktivitas yang dilakukan. Dewasa ini penggunaan internet oleh masyarakat sebagai media komunikasi dan berinteraksi semakin luas digunakan, hal ini tidak terlepas dari terciptanya berbagai aplikasi jejaring sosial seperti Facebook, Twitter, WhatsApp, Line dan lain-lain. Begitu juga halnya dengan dunia bisnis, banyak bermunculan perusahaan-perusahaan E-Commerce yang menawarkan berbelanja secara online, dengan berbagai flatform penawaran dan pembayaran transaksi melalui media internet dimana transaksi tersebut bisa dilakukan dengan mudah dengan bantuan ponsel pintar atau lebih dikenal dengan smartphone.

Lima besar vendor smartphone di Indonesia mendominasi 80 persen dari total pangsa pasar. Persentase ini tumbuh 65 persen dari tahun lalu. Dari website resmi Counterpoint, diketahui penguasa pasar ponsel Indonesia selama Q3 2019 berturutturut adalah Samsung (22\%), Xiaomi (20\%), Oppo (19\%), Vivo (13\%), dan Realme (11\%).Samsung masih menjadi pemimpin pasar (market leader), namun persaingan dalam industri ini semakin ketat terutama persaingan dengan vendor dari Cina dimana secara berurutan posisi kedua dan seterusnya diduduki oleh produk smartphone Cina.

Samsung masih menjadi pemimpin pasar (market leader), namun selisih pangsa pasarnya dengan ponsel- ponsel pabrikan dari Cina sangat tipis. Merek Tiongkok memegang empat dari lima posisi teratas dengan 65\% pangsa pasar berdasarkan volume. Persaingan dalam industri ini semakin ketat terutama persaingan dengan vendor dari Cina yang dari tahun ke tahun mengalami pertumbuhan oleh sebab itu Samsung tidak boleh lengah dan terus mencari strategi terbaik agar tetap bisa menjadi pemimpin pasar.

Kepuasan pelanggan merupakan salah satu kunci keberhasilan suatu bisnis. Banyak kegagalan bisnis terjadi karena pelanggan dikecewakan sehingga mereka mencari alternatif ke produk sejenis lainnya. Oleh karena itu hampir setiap perusahaan saat ini menyadari pentingnya arti pelanggan bagi perusahaan dan berupaya keras untuk dapat memberikan kepuasan kepada pelanggan. Karena dengan pelanggan yang puas, keuntungan akan datang dengan sendirinya, seperti dikemukakan Paul Allaire (Xerox),'Jika kami melakukan apa yang baik bagi pelanggan, bagian pasar dan laba operasi kami akan datang dengan sendirinya".

Menurut Kotler (2004), menyatakan kunci dalam mempertahankan pelanggan adalah kepuasan pelanggan. Pelanggan yang merasa puas akan memberikan 
keuntungan terhadap perusahaan, seperti: Membeli lebih banyak dan setia lebih lama;; Membeli jenis produk baru atau produk yang disempurnakan dari perusahaan; Mengumpulkan pujian bagi perusahaan dan produknya kepada orang lain; Kurang memperhatikan merek dan iklan pesaing, serta kurang sensitif terhadap harga; Memberikan gagasan baru atas barang atau jasa perusahaan

\section{TINJAUAN PUSTAKA}

\section{Kualitas Produk (Quality Product)}

Kualitas produk adalah suatu nilai dari produk atau jasa, dimana nilai produk atau jasa sesuai dengan apa yang diharapkan atau melebihi apa yang diharapkan sehingga produk atau jasa tersebut dapat memenuhi kebutuhan pemakainya (Kotler dan Amstrong, 2001). Kualitas yang baik dari suatu produk akan menghasilkan kepuasan konsumen. Suatu produk dapat dikatakan berkualitas apabila produk tersebut dapat memenuhi keinginan dan kebutuhan sesuai dengan yang diharapkan atau melebihi apa yang diinginkan konsumen. Menurut David (dalam Umar, 2000) untuk menentukan kualitas barang dapat melalui 8 dimensi yaitu : (a) performance; (b) features; (c) reliability; (d) conformance; (e) durability; (f) service ability; (g) aesthetics; dan (h) fit and finish.

\section{Price Fairness}

Antara Harga dan kepuasan menunjukkan bahwa tingkat dari kepuasan tergantung pada faktor kualitas jasa, mutu, produk, harga, situasi, dan faktor pribadi (Bei et al, 2001). Harga adalah sejumlah uang yang harus dikorbankan oleh konsumen untuk mendapatkan barang atau service (Bei et al, 2006). Secara rinci, konsumen cenderung untuk mempertimbangkan hubungan antara harga dan harapan mereka tentang capaian dari produk yang ingin dibeli. Karenanya, harga jual mungkin dibandingkan dengan suatu pengalaman sebelum dari pembeli atau suatu harapan yang adil (Hermann et al, 2007). Konsekuensinya, jika para pembeli merasa bahwa manfaat yang ditawarkan oleh produk sehubungan dengan dirasa pengorbanan tinggi, mereka akan lebih merasa bahwa harga adalah adil, hal tersebut disebut sebagai Price Fairness (Monroe, 1985). Menurut Matzler (2007) Price Fairness adalah persepsi konsumen dimana perbedaan antara harga yang diterima layak dibandingkan dengan yang lain, dapat dipertimbangkan atau harga yang bisa diterima. Pada studi lain menunjukkan bahwa harga yang dirasakan oleh

konsumen merupakan faktor penting yang digunakan konsumen dalam menilai kualitas (Hermann et al, 2001). Kewajaran harga telah digambarkan sebagai suatu hasil atau proses untuk menjangkau suatu hasil yang layak bisa diterima atau adil (Martin Consuegra et al, 2007) Ada tiga "harga acuan" konsumen ketika menilai kewajaran harga (Martin Ruiz et al, 2008) : Harga di masa lalu Harga yang diterapkan oleh competitor Biaya (harga) yang dikenakan oleh perusahaan Jika harga yang 
dirasakan konsumen lebih rendah, maka pengorbanan yang diberikan juga akan lebih rendah (Zeithaml, 1998). Konsumen pada barang jasa secara aktual memberi nilai terhadap harga yang tinggi sebab harga tersebut menggambarkan prestise/ image tentang kualitas, atau perolehan benefit tertentu yang khusus (Yazid, 2003:64). Kewajaran harga (price fairness) melibatkan suatu perbandingan dari harga prosedur dengan suatu standar yang bersangkutan, acuan, atau norma (Martin-Consuegra et al, 2007).

\section{Citra Merek (Brand Image)}

Citra Merek adalah sekumpulan assosiasi merek yang terbentuk dan melekat dalam benak konsumen terhadap suatu merek (Rangkuti, 2004) . Pengertian brand image menurut Kotler (2000) adalah pada mulanya konsumen mengembangkan sekumpulan keyakinan merek tentang dimana posisi setiap merek dalam masingmasing atribut. Kumpulan dari keyakinan atas suatu merek tersebut akan membentuk brand image (citra merek). Brand image (citra merek) merupakan sebuah rangkaian asosiasi merek yang saling berhubungan. Semakin banyak asosiasi yang saling berhubungan maka akan semakin kuat brand image yang dimiliki oleh merek tersebut (Rangkuti, 2004). Citra merek berpengaruh secara positif terhadap pembentukan loyalitas (Sondoh Jr dkk, 2007).

Menurut Simamora (2004), ada tiga indikator dari brand image yaitu:

a. Citra Perusahaan (Corporation Image) adalah sekumpulan asosiasi yang dipersesikan konsumen terhadap perusahaan yang membuat suatu produk atau jasa. Citra pembuat meliputi: popularitas, kredibilitas serta jaringan perusahaan.

b. Citra Konsumen (User Image) adalah sekumpulan asosiasi yang dipersepsikan konsumen terhadap pemakai yang menggunakan suatu barang atau jasa. Citra konsumen meliputi : pemakai itu sendiri, gaya hidup/kepribadian, serta status sosialnya.

c. Citra Produk (Product Image) adalah sekumpulan asosiasi yang dipersepsikan konsumen terhadap suatu produk. Citra produk meliputi artibut produk tersebut, manfaat bagi konsumen, penggunanya, serta jaminan.

Peter \& Olson (dalam Lutiary Eka Ratri, 2007) Citra merek didefinisikan sebagai persepsi konsumen dan preferensi terhadap merek, sebagaimana yang direfleksikan oleh berbagai macam asosiasi merek yang ada dalam ingatan konsumen.

\section{Kepercayaan Merek ( Brand in trust)}

Menurut Delgado (2003), Kepercayaan merek adalah perasaan aman yang dimiliki konsumen akibat dari interaksinya dengan sebuah merek, yang berdasarkan persepsi bahwa merek tersebut dapat diandalkan dan bertanggung jawab atas kepentingan dan keselamatan dari konsumen. Lau dan Lee (1999) mendefinisikan trust in brand sebagai kesediaan konsumen untuk percaya pada merek yang dihadapkan dengan resiko dan mempunyai ekspektasi bahwa merek akan menghasilkan outcome 
yang positif dengan memasukan unsur willingness (kesediaan). Kemudian Sheth dan Parvatiyar (1995) dalam huang et al. (2014) juga menegaskan bahwa logika di balik keberadaan merek adalah untuk mengirimkan kepercayaan ke pasar, terutama ketika kontak langsung antara konsumen dan perusahaan tidak mungkin terjadi.

\section{Kepuasan Pelanggan}

Menurut Kotler, 1994 (dalam Tjptono 2006) .Kepuasan pelanggan adalah tingkat perasaan seseorang setelah membandingkan kinerja (hasil) yang ia rasakan dibandingkan dengan harapannya. Sedangkan menurut Tjiptono (2006) Kepuasan atau ketidakpuasan pelanggan terhadap evaluasi ketidaksesuaian atau diskonfirmasi yang dirasakan antara harapan sebelumnya (atau norma kinerja lainnya) dan kinerja produk yang dirasakan setelah pemakainnya.

Kemudian menurut Kotler (2004), menyatakan kunci dalam mempertahankan pelanggan adalah kepuasan pelanggan. Pelanggan yang merasa puas akan memberikan keuntungan terhadap perusahaan, seperti: (1) Membeli lebih banyak dan setia lebih lama, (2) Membeli jenis produk baru atau produk yang disempurnakan dari perusahaan, (3) Mengumpulkan pujian bagi perusahaan dan produknya kepada orang lain, (4) Kurang memperhatikan merek dan iklan pesaing, serta kurang sensitif terhadap harga, (5) Memberikan gagasan baru atas barang atau jasa perusahaan

\section{METODE PENELITIAN}

Penelitian ini merupakan penelitian yang menggunakan data primer dengan metode survei. Penelitian survei adalah penelitian yang pengambilan data langsung ke lapangan yang dilakukan pada populasi yang besar maupun kecil, tetapi data yang diambil adalah data sampel dari populasi yang dianggap memenuhi syarat untuk dijadikan sampel. Instrumen penelitian yang digunakan adalah pengumpulan data primer dengan cara menyebarkan kuesioner kepada para responden. Penelitian dilakukan di Banjarmasin terhadap masyarakat pengguna/pemilik Handphone Samsung.

Populasi dalam penelitian ini adalah seluruh masyarakat yang memiliki dan menggunakan Handphone Samsung, dimana jumlah populasi tidak bisa diketahui secara pasti karena setiap saat bisa terjadi transaksi pembelian Handphone Samsung yang menyebabkan populasi selalu bertambah.

Dari populasi tersebut dipilih sampel. Ukuran sampel (sample size) ditetapkan berdasarkan 10 x jumlah variabel (Roscoe, dalam Sugiyono,2008), sehingga jumlah sampel minimal yang dalam penelitian ini adalah sebanyak $10 \times 5=50$ responden. Adapun jumlah sampel dalam penelitian ini adalah 125 responden, sehingga telah memenuhi syarat minimal sampel. 


\section{KERANGKA KONSEP PENELITIAN}

Kerangka konseptual model dalam penelitian ini disusun berdasarkan kajian teoritis maupun empiris adalah sebagai berikut :
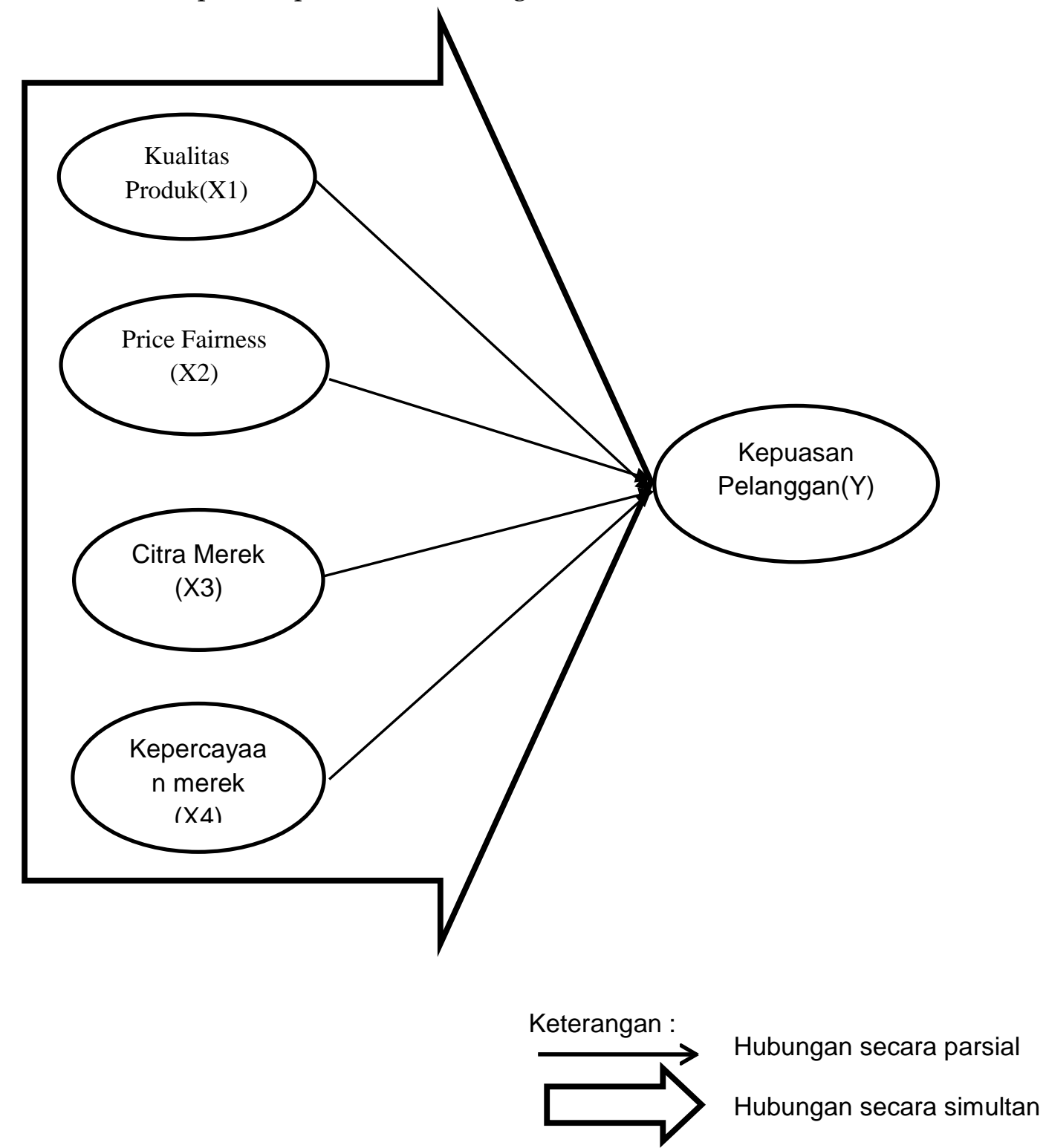

Gambar 1, Kerangka Konseptual Model Penelitian 


\section{HIPOTESIS PENELITIAN}

Berdasarkan kerangka konseptual tersebut, maka dapat disusun hipotesis penelitian sebagai berikut :

1. Kualitas Produk, Price Fairness, Citra Merek, dan Kepercayaan Merek berpengaruh signifikan secara simultan terhadap Kepuasan Pelanggan.

2. Kualitas Produk, Price Fairness, Citra Merek, dan Kepercayaan Merek berpengaruh signifikan secara parsial terhadap Kepuasan Pelanggan.

\section{HASIL PENELITIAN DAN PEMBAHASAN}

\section{Uji Validitas dan Reliabilitas}

Uji Validitas dan Reliabilitas instrumen penelitian dilakukan menggunakan program SPSS for windows release 22.0. Berdasarkan Hasil uji Validitas dapat dismpulkan bahwa secara keseluruhan instrumen dari variabel penelitian adalah valid karena memiliki nilai koefesien korelasi $r>0,3$. Demikian juga terhada hasil uji reliabilitas dapat disimpulkan bahwa seluruh nilai alpha lebih besar dari 0,6, sehingga semua instrumen dalam penelitian ini adalah reliabel.

\section{Uji Asumsi Klasik}

\section{Uji Normalitas}

Pengujian normalitas dalam penelitian ini dilakukan dengan uji kolmogorosmirnov (goodness of fit). Kriteria dalam pengujian ini adalah sebagai berikut (Ghozali, 2001). Jika Probabilitas/sig > 0,05 maka distribusi normal. Jika Probabilitas / sig < 0,05 maka berdistribusi tidak normal. Hasil uji normalitas kolmogorov-smirnov menunjukkan, nilai signifikan yang dihasilkan sebesar 0,200 $>0,05$ maka dapat disimpulkan bahwa data tergolong berdistribusi normal.

\section{UJi Heteroskedasitisitas}

Deteksi terjadinya heteroskedastisitas dilakukan dengan melihat ada tidaknya pola tertentu pada grafik, dimana sumbu $X$ dan $Y$ yang telah diprediksi, dan sumbu $\mathrm{X}$ adalah residual ( $\mathrm{Y}$ prediksi - Y sesungguhnya) yang telah di studentized (Ghozali, 2006:105). Dasar analisis. Jika ada pola tertentu, seperti titik-titik yang ada membentuk pola tertentu yang teratur (bergelombang, melebar kemudian menyempit), maka mengidentifikasikan telah terjadi heteroskedastisitas. Jika tidak ada pola yang jelas, serta titik-titik menyebar di atas dan di bawah angka 0 pada sumbu Y, maka tidak terjadi heteroskedastisitas.

Hasil grafik scater plot terlihat bahwa penyebaran data menyebar di atas dan di bawah angka 0 dan tidak membentuk pola tertentu, yang berarti tidak terjadi heteroskedastisitas. 


\section{Uji Multikolinearitas}

Uji multikolinearitas bertujuan untuk menguji apakah model regresi ditemukan adanya korelasi antar variabel independen. Multikolinearitas dapat dideteksi dengan nilai tolerance dan nilai Variance Inflation Factor (VIF). Berdasarkan hasil perhitungan dapat diketahui bahwa nilai tolerance untuk Kualitas Produk (X1) adalah sebesar 0,659 dan nilai VIF sebesar 1,518. Nilai tolerance pada Price Fairness (X2) adalah sebesar 0,814 dan nilai VIF sebesar 1,228. Nilai tolerance pada Citra Merek (X3) adalah sebesar 0,690 dan nilai VIF sebesar 1,450. Nilai tolerance pada Kepercayaan Merek (X4) adalah sebesar 0,687 dan nilai VIF sebesar 1,456. Berdasarkan hasil tersebut tidak ada nilai tolerance yang $<0,010$ dan tidak ada nilai VIF yang $>10$, maka dapat disimpulkan bahwa tidak terjadi multikoliearitas antar variabel bebas dalam model regresi tersebut.

\section{HASIL ANALISIS REGRESI LINEAR BERGANDA}

Analisis regresi linear berganda bertujuan untuk mengetahui pengaruh variabel Kualitas Produk, Price Fairness, Citra Merek dan Kepercayaan Merek terhadap Kepuasan Pelanggan. Analisis regresi dalam penelitian ini menggunakan program SPSS for window release 22.0 seperti terlihat pada tabel di bawah ini.

\section{Tabel 3. Uji Regresi Berganda}

\section{Coefficients $^{\mathrm{a}}$}

\begin{tabular}{|l|r|r|r|r|r|}
\hline & \multicolumn{2}{|c|}{$\begin{array}{c}\text { Unstandardized } \\
\text { Coefficients }\end{array}$} & $\begin{array}{c}\text { Standardized } \\
\text { Coefficients }\end{array}$ & & \\
\cline { 2 - 4 } Model & $\mathrm{B}$ & $\begin{array}{c}\text { Std. } \\
\text { Error }\end{array}$ & Beta & $\mathrm{t}$ & \multicolumn{1}{c|}{ Sig. } \\
\hline (Constant) & 1,314 & 1,456 & &, 903 &, 368 \\
Product Quality &, 027 &, 060 &, 041 &, 460 &, 646 \\
Price Fairness &, 087 &, 065 &, 108 & 1,339 &, 183 \\
Brand Image &, 165 &, 073 &, 198 & 2,260 &, 026 \\
Brand Trust &, 502 &, 107 &, 411 & 4,679 &, 000 \\
\hline
\end{tabular}

a. Dependent Variable: Satisfaction

Berdasarkan Tabel 3 di atas, dapat ditulis persamaan model regresi penelitian ini sebagai berikut:

$$
\mathrm{Y}=1,314+0,027(\mathrm{X} 1)+0,087(\mathrm{X} 2)+0,165(\mathrm{X} 3)+0,502+\mathrm{e}
$$


Tabel 5, Uji ANOVAa

\begin{tabular}{|c|c|c|c|c|c|c|}
\hline \multicolumn{2}{|c|}{ Model } & $\begin{array}{l}\text { Sum of } \\
\text { Squares }\end{array}$ & $\mathrm{df}$ & $\begin{array}{l}\text { Mean } \\
\text { Square }\end{array}$ & $\mathrm{F}$ & Sig. \\
\hline \multirow[t]{3}{*}{1} & Regression & 164,107 & 4 & 41,027 & 17,347 &, $000^{\mathrm{b}}$ \\
\hline & Residual & 281,441 & 119 & 2,365 & & \\
\hline & Total & 445,548 & 123 & & & \\
\hline
\end{tabular}

a. Dependent Variable: Satisfaction

b. Predictors: (Constant), Brand Trust, Price Fairness, Brand Image, Product Quality

Tabel 6. R Square

Model Summary

\begin{tabular}{|l|r|r|r|r|r|}
\hline Model & R & R Square & $\begin{array}{c}\text { Adjusted R } \\
\text { Square }\end{array}$ & $\begin{array}{l}\text { Std. Error of } \\
\text { the Estimate }\end{array}$ & $\begin{array}{c}\text { Durbin- } \\
\text { Watson }\end{array}$ \\
\hline 1 &, $607^{\mathrm{a}}$ &, 368 &, 347 & 1,5379 & 1,435 \\
\hline
\end{tabular}

a. Predictors: (Constant), Brand Trust, Price Fairness, Brand Image,

Product Quality

b. Dependent Variable: Satisfaction

Berdasarkan hasil perhitungan besarnya koefesien korelasi adjusted R Square adalah sebesar 0,368. Hal ini berarti 36,8 \% variasi dari Kepuasan Pelanggan dapat dijelaskan oleh keempat variabel independen yaitu Kualitas Produk, Price Fairness, Citra Merek, dan Kepercayaan Merek. Sedangkan sisanya sebesar 63,2\% dijelaskan oleh faktor - faktor lain diluar model.

\section{Uji Hipotesis}

\section{Uji Hipotesis Secara Simultan(Uji Statistik F)}

Uji F digunakan untuk mengetahui pengaruh secara bersama-sama variabel Kualitas Produk, Price Fairness, Citra Merek, dan Kepercayaan Merek terhadap Kepuasan Pelanggan.

Dari uji ANOVA atau F test didapat F hitung sebesar 17,347 dengan probabilitas signifikansi 0.000. Sehingga hipotesis ini diterima karena probabilitas signifikansi jauh lebih kecil dari 0.05, maka dapat dikatakan bahwa Kualitas Produk, Price 
Fairness, Citra Merek, dan Kepercayaan Merek secara bersama-sama berpengaruh signifikan terhadap Kepuasan Pelanggan.

\section{Uji Hipotesis Secara parsial(Uji Statistik t)}

Uji $\mathrm{t}$ digunakan untuk mengetahui pengaruh secara parsial masing-masing Kualitas Produk, Price Fairness, Citra Merek dan Kepercayaan Merek terhadap Kepuasan Pelanggan.

Hipotesis pertama menyatakan bahwa Kualitas Produk berpengaruh signifikan terhadap Kepuasan Pelanggan. Hipotesis ini ditolak karena probabilitas signifikansi $>$ 0,05 yaitu 0.646. Hal ini berarti bahwa Kualitas Produk tidak berpengaruh signifikan terhadap Kepuasan Pelanggan. Hasil ini bertentangan dengan temuan Uddin dan Ahkter, (2012), yang menyatakan bahwa kualitas produk berpengaruh signifikan terhadap kepuasan pelanggan.

Hipotesis kedua menyatakan bahwa Price Fairness berpengaruh signifikan terhadap Kepuasan Pelanggan. Hipotesis ini ditolak karena probabilitas signifikansi $>0,05$ yaitu 0.183. Hal ini berarti bahwa Price Fairness tidak berpengaruh signifikan terhadap Kepuasan Pelanggan. Hasil ini bertentangan dengan temuan Uddin dan Ahkter, (2012), Bei et al, (2001).

Hipotesis ketiga menyatakan bahwa Citra Merek berpengaruh signifikan terhadap Kepuasan Pelanggan. Terbukti hipotesis ini diterima karena probabilitas signifikansi < 0,05 yaitu 0.026. Hal ini berarti bahwa Citra Merek berpengaruh signifikan terhadap Kepuasan Pelanggan. Hasil ini sesuai dengan studi Dunuwille , Pathmini(2016).

Hipotesis keempat menyatakan bahwa Kepercayaan Merek berpengaruh signifikan terhadap Kepuasan Pelanggan. Terbukti hipotesis ini diterima karena probabilitas signifikansi < 0,05 yaitu 0.000. Hal ini berarti bahwa Kepercayaan Merek berpengaruh signifikan terhadap Kepuasan Pelanggan. Hasil ini sesuai dengan temuan Roshana, Gul(2014).

Berdasarkan hasil uji secara parsial, diketahui bahwa variabel Kepercayaan Merek mempunyai pengaruh yang paling dominan terhadap Kepuasan Pelanggan, karena mempunyai nilai koefesien regresi terbesar yaitu 0,411.

\section{IMPLIKASI PENELITIAN}

1. Variabel produk tidak berpengaruh signifikan terhadap kepuasan pelanggan. Hal ini menunjukkan bahwa kualitas produk tidak mempengaruhi kepuasan pelanggan. Hal ini menunjukkan bahwa kepuasan pelanggan tidak selalu ditentukan oleh kualitas suatu produk, berarti mereka kurang memperhatikan dan mempertimbangkan kualitas produk dalam menentukan kepuasan. Temuan ini tidak sejalan dengan temuan para peneliti terdahulu yang mengatakan bahwa kualitas produk merupakan faktor yang mempengaruhi atau menentukan kepuasan. 
Hal ini mungkin terjadi karena selama ini konsumen menganggap Samsung selalu menghasilkan produk yang berkualitas, sehingga mereka tidak memperhatikan lagi variabel ini, oleh karena itu variabel ini tidak lagi menjadi faktor penentu kepuasan pelanggan.

2. Variabel price fairness tidak berpengaruh signifikan terhadap kepuasan pelanggan. Hal ini menunjukkan bahwa price fairness bukan menjadi penentu kepuasan pelanggan. Hal ini tidak sesuai dengan penelitian terdahulu yang menyatakan bahwa harga yang wajar mempengaruhi kepuasan.

Fenomena ini mungkin terjadi karena Pelanggan menganggap bahwa harga yang tetapkan Samsung dianggap wajar sesuai dengan kualitas dan manfaat yg di terima. Sehingga bagi mereka variabel ini tidak mempengaruhi atau tidak menjadi penentu kepuasan mereka.

3. Citra merek berpengaruh signifikan terhadap kepuasan pelanggan. Hal ini bermakna bahwa citra merek menjadi penentu kepuasan pelanggan, ini berarti bahwa semakin baik citra merek dimata pelanggan maka mereka semakin puas

4. Kepercayaan merek berpengaruh signifikan dan dominan terhadap kepuasan pelanggan. Hal ini menunjukkan bahwa selama ini kepercayaan merek penjadi faktor utama yang mempengaruhi kepuasan pelanggan. Semakin percaya dan yakin konsumen terhadap suatu merek maka mereka semakin puas.

\section{KESIMPULAN}

Berdasarkan hasil penelitian, maka dapat disimpulkan sebagai berikut :

1. Variabel Kualitas Produk, Price Fairness, Citra Merek, dan Kepercayaan Merek berpengaruh signifikan secara simultan terhadap Kepuasan Pelanggan.

2. Variabel Kualitas Produk Dan Citra Merek, secara parsial tidak berpengaruh signifikan terhadap Kepuasan Pelanggan. Sedangkan variabel Price Fairness dan Kepercayaan Merek berpengaruh signifikan terhadap Kepuasan Pelanggan.

3. Variabel Kepercayaan Merek merupakan variabel yang paling dominan mempengaruhi Kepuasan Pelanggan.

\section{KETERBATASAN PENELITIAN}

Sampel dalam penelitian ini dirasa masih sedikit, untuk penelitian yang akan datang hendaknya menggunakan sampel yang lebih besar, mengingat handphone Samsung memiliki pengguna yang sangat banyak.

\section{DAFTAR PUSTAKA}

Bei, L. T., and Chaio, Y.C. 2006. “ The Deterninant of Costumer Loyalty : An Analysis of Intangible Factors In Three Service Industries ", International Journal of Consumer Satisfaction, Vol. 16 No. 384, pp. 162-177. 
Delgado-Ballester, Elena, Munuera-Aleman, Jose Louis \& Yague-Guillen, Maria Jesus. (2003). Development and Validation of A Brand Trust Scale", Internationa, Journal of Market Research, vol. 45/1, p. 35-53.

Dunuwille, Pathmini(2016) Brand image and customer satisfaction in mobile phone market: study based on customers in kandy district.

Ghozali, Imam, 2005, Aplikasi Multivariate Dengan Program SPSS, Badan Penerbit Diponegoro.

Roshana, Gul, 2014, The Relationship between Reputation, Customer Satisfaction, Trust, and Loyalty

Hermann, A,. ia, L., Monroe, K. B., and Huber, F. 2007. “ The Influence of Price Fairness on Customer Satisfaction : An Empirical Test in the Context of automobile Purchase", Journal of Product \& Brand Management, Vol. 16 No. 1, pp. 49-58.

Huang, C. C, et. al. (2014). The Relationship Among Brand Equity, Customer Satisfaction and Brand Resonance to Repurchase Intention of Cultural and Creative Industries in Taiwan, IJOI .

Kotler, Philip(2004) Manajemen Pemasaran, Edisi Milenium, Jilid 1, PT Prenhallindo, Jakarta.

Kotler, Philip, dan Amstrong, Gary, 2001, Dasar-dasar Pemasaran, Jilid Satu, Edisi Kesembilan, Penerbit PT. Gramedia Pustaka Utama : Jakarta

Lau, G.T. and Lee, S.H. (1999). Consumers'trust in a brand and the link to brand loyalty, journal of market Focused Management, Vol.4, pp.341-70.

Martin-Consuegra, D., Molina, A. and Esteban, A. 2007. “ An Integrated Model of Price, Satisfaction, and Loyalty: An Empirical Analysis in the Service Sector ", Journal of Produk \& Brand Management, Vol. 16 No. 7,pp. 459-468.

Martin-Ruiz, D., and Rondan-Cataluna, F. J. 2008. " The Nature and Consequenses of Price Unfairness in Service: A Comparison to tangible Goods". International Journal of Service Industry Management, Vol. 19 No. 3,pp. 325-352.

Matzler, K., Brigit, R., and Faullant, R. 2007. “ Dimensions of Price satisfaction : A Replication And Extention ". The International Journal of Bank Marketing, Vol. 25 No. 6,pp. 394-405.

Monroe, K. and Krishnan, R. 1985, "The effect of price on subjective product evaluations", in Jacoby, J. and Olson, J. (Eds), Perceived Quality: How Consumers View Stores and Merchandise, Lexington Books, Lexington, MA, pp. 209-32.

Uddin, Mohammed Belal dan Ahkter Bilkis, (2012) Customer Satisfaction In Mobile Phone Services In Bangladesh: a Survey Research

Umar Husein. 2000. Riset Pemasaran dan Perilaku Konsumen. Jakarta: PT.Gramedia Pustaka Utama.

Peter, J. Paul \& Olson, Jerry C. (2000).PerilakuKonsumen dan Stretegi Pemasaran (Dimas Sihombing: Terjemahan). Jilid Kedua. Edisi Keempat. Jakarta: Erlangga 
Rangkuti, 2004, http : diglib.petra.ac.id, Tanggal akses 18/08/2019.

Rasheed, Hafiz Muhammad Wasif dan Muhammad Khalid Anser, 2017. Effect on Brand Loyalty in Mobile Phone Purchasing (A Case Study in Bahawalpur, Pakistan)

Sondoh, Stephen, Maznah Wan Omar, Nabsiah Abdul Wahid, Ishak Ismail, Amran Harun, 2007, The Effect of Brand Image on Overall Satisfaction and Loyalty Intention in the Context of Color Cosmetic. Asian Academy of Management Journal, Vol. 12, No. 1, 83-107, Januari 2007.

Sugiyono, 2008, Metode Penelitian Bisnis, Cetakan Keduabelas, Penerbit Alfabeta Bandung.

Yazid, 2003, Pemasaran Jasa, Edisi Kedua, Ekonisia Fakultas Ekonomi UII, Yogyakarta.

Zeithaml, V. 1988, "Consumer perceptions of price, quality and value": a meansend model and synthesis of evidence", Journal of Marketing, Vol. 52, July, pp. 2-22. 